\title{
Exploring the Issues for the Success of Multichannel Network Businesses in Korea
}

\author{
Yoon-Jin Choi, Yonsei University, Seoul, Korea, Republic Of \\ Hee-Woong Kim, Yonsei University, Seoul, Korea, Republic Of
}

\begin{abstract}
With the increasing popularity of online video content like YouTube carries, multichannel network (MCN) businesses have appeared. MCNs are organizations that partner with individual creators. They support production, promotion, copyright management, monetization, and share a portion of the revenue. The activation of the MCN industry is indispensable for the growth of a rich content environment. Despite the diverse stakeholder relationships that characterize the MCN industry (e.g., the MCN, creator, brand, advertising agency, platform, and users) most previous studies focused only on the perspectives of the creators and MCN participants. This study aims to identify each stakeholder's viewpoint. Using an interview-based systems approach, we interviewed 40 stakeholders in the MCN industry. After using a Causal Loop Diagram (CLD) to analyze the key factors and interactions among the diverse stakeholders, we suggest activation propositions. This study offers theoretical and practical implications through comprehensive understanding of six different perspectives within this industry.
\end{abstract}

\section{KEYWORDS}

Branded Content, Causal Loop Diagram, CLD, Creator, Individual Media, MCN, Multichannel Network, System Dynamics, YouTube

\section{INTRODUCTION}

With the increasing popularity of watching videos on smart devices, personal broadcasting by individual creators has become part of the major media. Personal media refer to content produced and performed by individual content creators through the Internet video platform. According to Defy Media's 2014 surveyzza (Defy Media, 2015), viewers aged 13 to 24 in the Unites States watched social media like YouTube an average of 11.3 hours a day, while regular broadcasts for only 8.3 hours a day. These figures show that the influence of these personal creators already exceeds that of stars of pop culture and movies. According to Variety (2014), eight of the top 10 most influential stars in the United States in 2015 were from YouTube. YouTube star PewDiePie gained 47millions globally in 2015 while earning US\$12 million in revenue from YouTube (Variety, 2015).

The Chinese are also huge fans of creator content, with the MCN Wang Hong a highly popular purveyor of such content. Wang Hong (网红) is an abbreviation of Wang Hong Hongrun (网络红 人), which is a combination of "Internet" (网络) and "popular person" (红人). Popular Wang Hongs are highly successful financially by selling goods through their media. Zhang Dayi, one of China's best-known Wang Hong, reportedly earns US\$46 million a year. It is much higher than top Chinese actress, Fan Bingbin, who earns about US\$21 million a year (BBC, 2016). The Wang Hong economy has a value of more than US\$16 billion in the apparel market, which is one sixth of the total online

This article, originally published under IGI Global's copyright on December 20, 2019 will proceed with publication as an Open Access article starting on January 11, 2021 in the gold Open Access journal, Journal of Global Information Management (converted to gold Open Access January 1, 2021), and will be distributed under the terms of the Creative Commons Attribution License (http://creativecommons.org/ licenses/by/4.0/) which permits unrestricted use, distribution, and production in any medium, provided the author of the original work and 
apparel market (KOTRA, 2016). The Chinese data analysis company Analysis (易观智库) predicts that the Wang Hong industry will grow to US\$15.1 billion by 2018, up from US\$3.7 billion in 2015 .

As the influence of creators grows, Multi Channel Network (MCN), an industry that manages and commercializes creators, has emerged. The MCN industry is spreading worldwide with the popularity of creator content. Google estimates that by 2020 creator media will account for more than $70 \%$ of YouTube content (KyunghyangNews, 2018). MCN businesses support production, promotion, copyright management, and monetization and share a portion of the revenue. Among the MCN businesses all over the world, the case of Korea is noteworthy. Korea's growing MCN industry is led by firms. Similar implications are present in other countries where the MCN industry is beginning. Korea's MCN has implications for other countries because it is stabilizing its revenue model with content such as K-pop and K-beauty that is competitive globally.

Existing research related to the MCN industry remains at the level of analyzing the industry's current status without dealing with its main issue. Many studies describe the current status of the industry in the new screen ecology (Kang, 2015; Cunningham \& Silver, 2016; Kim, 2016). Some have examined the business model of the industry (Gardner, 2015; Song, 2016; Koh \& Youn, 2016), but most of these used a literature review method and limited interviews. Some recent studies have examined the relationships of stakeholders in MCN industry. Gardner and Lehnert (2016) focused on the relationship between MCN companies and creators. Yim (2016) researched the difference between legacy media and MCN companies. Lee and Song (2016) studied users' acceptance of creator content.

Activation of the MCN industry is essential for activation of a new media ecology. The biggest problem of the industry recently has been the lack of monetization despite its increased scale. Nevertheless, most of the previous studies do not deal with the major issues, but only the overall status of the industry. And although the MCN is an industry of diverse stakeholder relationships (i.e., MCN participants, MCN creators, brand managers, advertising agency account executives, platform participants, and users), most previous studies have focused on the creators and MCN participants (Koh \& Yoon, 2016; Lee \& Song, 2016). The views of numerous other stakeholders have not been considered.

Our research is motivated by this gap in the research and also by the practical problems faced by MCN service providers in leveraging monetization of the industry. Thus, this study aims to explore issues in the MCN businesses and suggest propositions for its success in Korea. Activation strategies in Korea have implications for other countries that are introducing MCNs. For this purpose, we examine the viewpoints of participating stakeholders. Using an interview-based exploratory approach, we interview 40 stakeholders in six major categories of stakeholders. The 40 interviewees consist of 24 experts and 16 users. The MCN participants especially are carefully selected from six different representative MCN companies. Based on the data collected through the interviews, we analyze the interactions among the diverse stakeholders by using a causal loop diagram (CLD) and suggest propositions for each issue. These propositions are validated by expert focus group discussions (FGD). After one validation, the issues and propositions are revalidated a year later. This study offers theoretical and practical implications through comprehensive understanding of six different perspectives.

\section{CONCEPTUAL BACKGROUND}

\section{MCN Concept and Industry Status}

The MCN concept was first defined by Google. "Multi-Channel Networks (MCNs) are entities that affiliate with multiple YouTube channels, often to offer assistance in areas such as product, programming, funding, cross-promotion, partner management, digital rights management, monetization/sales, and/or audience development (YouTube, 2018)." Previous studies also defined the MCN concept similarly. "An MCN is any entity or organization that partners with content creators or directly produces a variety of distinctive content and works to perform business and 
Figure 1. MCN business stakeholders and business models

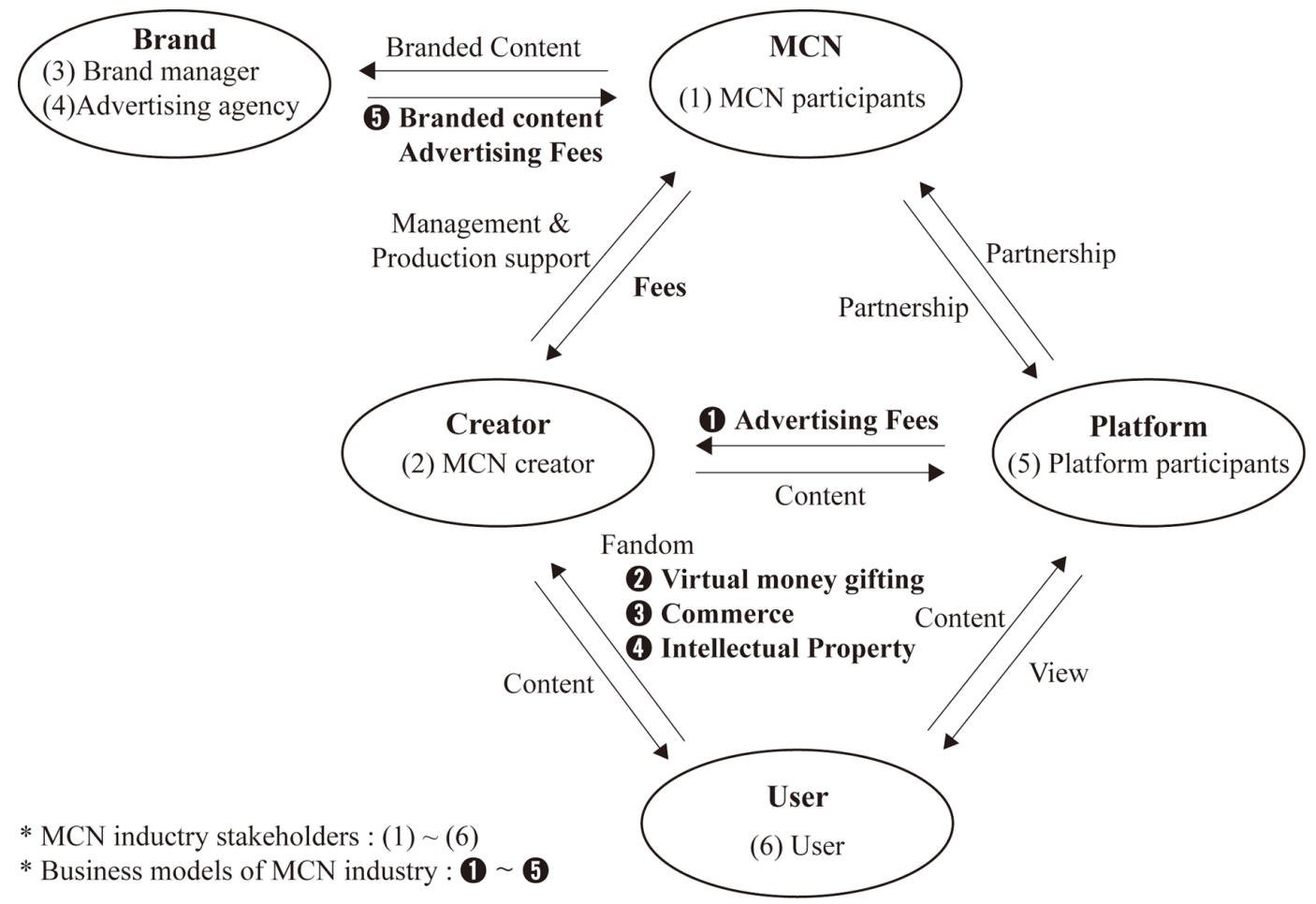

marketing functions via the platform whereby said content is released. (Gardner and Lehnert, 2016, p. 294)." "An MCN is a Google/YouTube-approved intermediary aggregating, affiliated with, and/or managing YouTube channels by 'offering their assistance in diverse areas, ranging from production to monetization, in exchange for a percentage of the ad revenue" (Cunningham et al., 2016, p. 1).

The structure of the ecosystem of MCN is outlined in Figure 1. The six main stakeholders in the MCN industry are as follows.

1. MCN participants: They work at MCN companies and perform activities such as creator management, content production support, and business account management.

2. MCN creators: Creators who create content, operate their channels, and belong to MCN companies.

3. Brand managers: They are the marketing communications officers of the brand. Their goal is to execute efficient and effective marketing communication campaigns by using various communication channels.

4. Advertising agencies: They propose, organize, and coordinate the creation and operation of marketing communication campaigns by linking MCNs and brands.

5. Platform participants: They work for platforms, such as YouTube and traditional media, through which MCN content is circulated.

6. Users: Platform users who frequently watch $\mathrm{MCN}$ creators' content.

The MCN industry began to emerge in the late 2000's and its expansion by global companies since 2010 has resulted in estimates of its total revenue at US\$10 billion globally. In the United States, the industry became prominent in 2013 when DreamWorks Animation acquired Awesomeness 
TV for US\$33 million and again the next year when Disney acquired Maker Studios for US\$500 million (Forbes, 2014). As shown in Table 1 China has the second largest MCN industry. According to analysts (易观智库) (2016), the Chinese Wang Hong industry will reach US\$ 16 billion in 2018, with an expected $2015 \sim 2018$ average annual growth rate of 59.4\%. The main revenue source for the Chinese MCN industry is commerce. Wang Hong has a value of more than US\$ 1 billion in the apparel sector, which is one sixth of the total online apparel market (KOTRA, 2016). Wang Hong management-focused MCN businesses appeared in 2016. They attracted US\$7.5 million to US\$15 million in investment.

In Korea, the size of the domestic market is US\$18 28 billion. CJ E\&M started the first MCN business, and it operates over 650 channels under the name of DIA TV. As for independent MCN companies, Treasure Hunter has attracted investment of US\$ 15 billion, MakeUs has attracted investment of US\$ 19 billion, Kongdoo-Company has gained US\$1.9 million, and SandboxNetwork has attracted US\$ 1.9 million (Kang, 2015). Furthermore, domestic broadcasters such as KBS and entertainment management companies like SM Entertainment are also entering the MCN business.

\section{MCN Business in Korea}

The unique aspect of MCN business in Korea is that enterprises are leading the industry. The Korean MCN business differs from MCNs in the United States and China. Korea's MCNs are characterized by firm-led growth (Koh and Youn, 2016), unlike the spontaneous growth of U.S. MCNs. Korea's is not a self-sustaining formulation in which the number of creators grows and the number of viewers increases accordingly. MCNs in China are very popular because of the popularity of Wang Hong. Its influence is widespread because it is based on the huge population of China. A famous Wang Hong called Papi Zhang drew 20 million people, and the broadcast was stopped because of a traffic overload (Korea Creative Content Agency, 2016). However, unlike most countries, China blocks Google, YouTube, Facebook, etc., and allows only Chinese services. Another difference in China is that its MCN industry is centered on eight major platforms (Yizhibo (一直播), Meipai (美拍), Huajiao (花椒), Douyu (斗鱼), Youku (优酷), Baidu, Panda TV (熊猫TV), Toutiao (今日头条)).

An understanding of Korea's MCN industry is important for two reasons. First, unlike in the United States and China, it has implications for countries with newly introduced MCN industries. In most countries except the United States, there is a strong possibility that MCN will take the form

Table 1. Major global and Korean MCN companies

\begin{tabular}{|c|c|c|c|c|}
\hline Division & MCN & Established & $\begin{array}{l}\text { Investment } \\
\text { attracted }\end{array}$ & Uniqueness \\
\hline \multirow{5}{*}{ Global } & Maker Studio & 2009 & $\$ 950$ million & Broad topics and ages \\
\hline & Fullscreen & 2011 & $\$ 300$ million & $\begin{array}{l}\text { Actively collaborates with the } \\
\text { brand }\end{array}$ \\
\hline & Machinima & 2007 & $\$ 42$ million & Game engines, graphics \\
\hline & Awesomness TV & 2012 & $\$ 117$ million & Comedy aimed at youth market \\
\hline & Stylehaul & 2011 & \$ 107 million & Beauty, fashion for women \\
\hline \multirow{3}{*}{ China } & Chipao(七炮) & 2016 & $\$ 15$ million & \\
\hline & $\begin{array}{l}\text { Chungingtao } \\
\text { (中樱挑) }\end{array}$ & 2016 & $\$ 7.5$ million & \\
\hline & Meakung(美空) & 2016 & $\$ 15$ million & \\
\hline \multirow{3}{*}{ Korea } & $\begin{array}{l}\text { CJ E\&M } \\
\text { (DIA tv) }\end{array}$ & 2013 & - & $\begin{array}{l}\text { Active international platform } \\
\text { alliance }\end{array}$ \\
\hline & Treasure Hunter & 2015 & $\$ 13.8$ million & $\begin{array}{l}\text { Fostering creators, Monthly } \\
\text { Active Visitor } 200 \text { million }\end{array}$ \\
\hline & Make Us & 2015 & $\$ 17$ million & $\begin{array}{l}\text { Digital Content Production } \\
\text { 'Dingo' }\end{array}$ \\
\hline
\end{tabular}


of an industry-led business rather than a self-sufficient MCN industry. China may not be a good model for other countries because few of them prohibit the use of global services, such as Google, YouTube, and Facebook. Among the alternatives, the best insights for other countries may come from an understanding of Korea's MCN industry.

Second, the Korean MCN content is competitive globally, with content such as K-pop and K-Beauty. Benchmarking Korea's MCN industry and its content competitiveness will have considerable influence on fledgling MCN undertakings in new countries. In fact, Korea's large MCN firms are attracting overseas investors because of their advances in the Southeast Asian and Chinese markets (Platum, 2017).

\section{Business Model of MCN Industry}

The MCN industry is rapidly growing in terms of number of viewers and amount of content, but the ongoing revenue model is not well-established. When new technologies or media develop, it is an early issue to find revenue models using the technology or media (Kim et al., 2015). According to previous research and media articles, the MCN industry has five major revenue models (See Figure 1).

The first of these is advertising fee distribution. Most video platforms make money by showing video ads either before or after the video content instead of letting users see the content ad free. The video platforms share this advertising revenue with the creators in proportion to the number of views. The second model uses virtual gifts of money. Viewers can give virtual gifts during live streaming broadcasts. These virtual money gifts are exchangeable for cash (e.g. "Super Chat" on YouTube and "Star Balloons" on Afreeca TV). Third, some MCNs pursue a commerce model in the form of influencer marketing. This approach capitalizes on the celebrity status attained by popular creators and the desire of their fans to emulate them. The social recommendations of these creators reduce customers' uncertainty and help their decision making (Lu et al., 2017). The fourth revenue model uses intellectual property (IP) rights. Among Korean MCN businesses, SandboxNetworks uses the IP model most actively. Comic books made with Dotty characters became best sellers and Dotty animations recorded the highest ratings among the animation channels. His character is also used in a variety of products bought by many targeted viewers (e.g., snacks, blocks, and dolls). Lastly, the most important, but still unstable, model for activating the MCN industry is branded content production. Branded content is a kind of marketing technique that attracts consumers' attention by combining advertising messages with content (Shin et al., 2014). According to previous studies on the MCN industry, the most important and major monetization model is branded content (Gardner, 2015; Song, 2016; Koh \& Youn, 2016).

\section{Previous Research on MCN}

Most of the studies trying to examine the current status of the MCN industry rely on a literature review. Some studies have examined the current status of the MCN industry (Kang, 2015; Cunningham \& Silver, 2016; Kim, 2016) from the viewpoint of a new media ecology. Kim (2016) decided that the biggest task was becoming profitable and presented a solution based on content, platform, network, and devise (CPND). Some studies also examined the industry's business model (Gardner, 2015; Song, 2016; Koh \& Youn, 2016). The main business model can be summarized as advertising, donations, and merchandising (Gardner \& Lehnert, 2016). But most of these studies used a literature review method and only limited interviews. As a consequence of this approach, only a limited effort has been made to comprehensively reflect the views of all stakeholders related to the industry's business model.

Some recent studies examined the relationships of stakeholders in the MCN industry. Gardner and Lehnert (2016) focused on the relationship between MCN businesses and content creators. Although the relationship between MCN businesses and creators involves an understanding of the industry, how it derives its business model, and the issues confronting it, such a narrow focus does not take into account the views of other stakeholders, thus imposing limitations on how to solve practical challenges. Yim (2016) researched the relationship between legacy media and MCN. However, the 
author focused on the countermeasures taken by the legacy media rather than on the activation of the MCN industry. Lee and Song (2016) merely focused on users in their study of users' acceptance of creator content.

In light of the lack of consideration given to the viewpoints of other stakeholders, this study aims to explore issues so far ignored in MCN businesses and advance propositions for their success in Korea. For this purpose, this study aims to explore issues in the MCN businesses and advance propositions for their success in Korea. For this purpose, we examined participating stakeholder's viewpoints in the MCN industry.

\section{METHODOLOGY}

We conducted an interview based an exploratory study to identify the key factors in activating the MCN industry and suggest an activation plan. After interviewing the various stakeholders, we used CLD to illustrate the causal and influential relationships among the factors. The qualitative model, causal diagram, is used to analyze the interactions of various phenomena and to predict their influence relationships by use of approaching systems thinking (Yu et al., 2013; Sterman, 2001).

\section{Interview-based Qualitative Study}

We interviewed persons in six major stakeholder categories. Our 40 interviewees consisted of 24 experts and 16 users. In qualitative research, relevance sampling is the most important element. We conducted our interviews of the relevant sample according to clear criteria. "It is their relevance to the research topic rather than their representativeness which determines the way in which the people to be studied are selected" (, 1998, p. 41). Representativeness is important, but relevance is even more so (Neuman, 2013).

With regard to the expert interviewees, we used quota sampling to ensure the representativeness of the interview samples. SixMCN participants were carefully selected from the representative MCN companies and bore titles of team leader or above. Thus, we could get a balanced grasp of the status of the MCN industry. In the creator sampling, we selected the representative genres of MCN content first, and after that, chose seven creators one by one in each genre so that we could grasp issues specific to each genre characteristic. In brand manager interviewee sampling, we selected three domestic and global brand participants who had collaborated with MCN creators. At the same time, four representatives from major advertising agencies were invited to participate in the interviews so that we could hear their opinions on the MCN industry. In addition, two platform participants closely related to MCN and traditional content industry participants were also interviewed to identify issues related to the MCN industry throughout the content industry. In the case of interviews for general users, their reasons for watching MCN creators' content were identified and reinforcing and balancing factors to activate the MCN industry were derived.

The purpose and content of the interviews differed according to the characteristics of the interviewees. Before the interviews, we sent an interview request by telephone or e-mail and sent questionnaires to those persons willing to be interviewed, so that the interview could be conducted legitimately (Shaw \& Wainwright, 2007). With the permission of the interviewee, each interview was digitally recorded (Jang et al., 2015). Interviews were typically conducted face-to-face for 40 minutes to 90 minutes. In those case in which face-to-face interviews were not possible, telephone interviews were conducted and also recorded.

\section{Causal Loop Diagram (CLD)}

CLD constructs a feedback loop using variables, arrows, and plus and minus signs (Lee et al., 2012). The arrows indicate causal relationships between variables. The starting point of the arrow is the causal variable, and the ending point is the affected variable. The plus and minus signs describe the 
causal direction: The plus sign indicates that two factors change in the same direction, and the minus sign means the sign changes in the other direction (Sterman, 2001).

When multiple causal connections form a closed loop, this is called a feedback loop (Akkermans, 2002). A feedback loop can be either positive or negative (Sutato, 2008). A positive loop is called a reinforcing loop because it has characteristics that enhance the change that occurs; a negative loop has a characteristic that acts in the direction of balancing the system and is called a balancing loop (Yu et al., 2013). This causal diagram is used as a qualitative model to analyze, and predict the effects of, the interactions of various phenomena through system analysis and qualitative simulation.

\section{RESULTS}

The factors influencing the activation of MCN industry are classified into those that reinforce and those that balance. We extracted the balancing and reinforcing factors from an interview-based case study (Lee et al., 2014). The results are composed of loops derived from the perspective of each stakeholder. Based on the results we found issues and suggested alternatives.

We analyzed the interview $\log$ s to derive the keywords, calculate their frequency, and then reflected them in our results (see Table 2). First, we analyzed the interview log and constructed variables of the CLDs based on the keywords each stakeholder used most frequently. These most frequently used words were considered to reflect their key interests. The key interests expressed most frequently are highlighted in the boxes in figures $2 \sim 5$. MCN participants are most interested in "MCN revenue" and "total number of views." A brand's is most interested in "achieving brand's marketing goal." A creator's major interest is "total number of views." And a platform \& user's paramount interest is "variety of good quality content."

Second, the most important variables can be identified overall. The most commonly mentioned variables were "total number of views" and "popularity of creators." These are the most common variables in all stakeholder groups in the MCN industry. The popularity of creators and the total number of views are fundamental to all stakeholders.

Third, we can identify specific variables important to each stakeholder. MCN participants talk a lot about "MCN's revenue" and focus on "MCN's profitability." Brand associates are concerned about a "creator's target influence" and a "creator's marketing influence" while at the same time considering "achieving brand's marketing goal" as the most important issue. In the case of creators, the "total number of views" and "profitability" are important, but "content autonomy" is also important. Platform \& users are most concerned with "user entry into the platform" through "variety of good quality content" but also are worried about "increasing suggestive content."

Fourth, we conducted interview log analysis to analyze how often each stakeholder used different words for the same concept. For example, $14.6 \%$ of brand and ad agency stakeholders used the words "creator control" when it comes to coordinating creators and advertisers in creating branded content, but creators and MCN representatives only used the same expression $4 \%$ and $4.4 \%$, respectively. Instead, $8.8 \%$ and $9.8 \%$ of creators and MCN representatives mentioned "content autonomy" in branded content production. In the collaborative process of making branded content, frequency analysis showed that each stakeholder's interest differs according to their position. In addition, the frequency of the use of each variable let us grasp how important each stakeholder considered the keywords. Although brands focus on delivering the desired message by controlling the creators to achieve their brand's marketing goals, the creators are very sensitive to infringement on their content autonomy and characteristics.

\section{MCN Participant's Perspective}

The CLD from an MCN participant's perspective is shown in Figure 2. First, the reinforcing loop generated by the management of the MCN is [R2] and [R4]. [R2] is a reinforcing loop that boosts the creator's ability to create content and increases the total number of views, which increases the revenue 
Table 2. Open coding results

\begin{tabular}{|c|c|c|c|c|c|c|c|c|}
\hline \multirow[t]{2}{*}{ Key variable } & \multicolumn{2}{|c|}{$\begin{array}{c}\text { MCN } \\
(6)\end{array}$} & \multicolumn{2}{|c|}{$\begin{array}{l}\text { Brand } \\
\quad(7)\end{array}$} & \multicolumn{2}{|c|}{$\begin{array}{l}\text { Creator } \\
(7)\end{array}$} & \multicolumn{2}{|c|}{$\begin{array}{l}\text { Platform \& User } \\
\text { (20) }\end{array}$} \\
\hline & Frq & $\%$ & Frq & $\%$ & Frq & $\%$ & Frq & $\%$ \\
\hline MCN revenue & 36 & $13.1 \%$ & 7 & $2.7 \%$ & 8 & $2.9 \%$ & 4 & $1.1 \%$ \\
\hline $\begin{array}{l}\text { Total number of } \\
\text { views }\end{array}$ & 33 & $12.0 \%$ & 23 & $8.8 \%$ & 36 & $13.1 \%$ & 41 & $11.5 \%$ \\
\hline $\begin{array}{l}\text { MCN's creator } \\
\text { support \& } \\
\text { investment }\end{array}$ & 25 & $9.1 \%$ & 4 & $1.5 \%$ & 25 & $9.1 \%$ & 12 & $3.4 \%$ \\
\hline $\begin{array}{l}\text { Popularity of } \\
\text { creators }\end{array}$ & 28 & $10.2 \%$ & 27 & $10.3 \%$ & 32 & $11.6 \%$ & 34 & $9.6 \%$ \\
\hline $\begin{array}{l}\text { Branded content } \\
\text { creation }\end{array}$ & 21 & $7.7 \%$ & 24 & $9.2 \%$ & 23 & $8.4 \%$ & 28 & $7.9 \%$ \\
\hline Creator control & 11 & $4.0 \%$ & 38 & $14.6 \%$ & 12 & $4.4 \%$ & 6 & $1.7 \%$ \\
\hline Content autonomy & 24 & $8.8 \%$ & 2 & $0.8 \%$ & 27 & $9.8 \%$ & 16 & $4.5 \%$ \\
\hline $\begin{array}{l}\text { User entry into the } \\
\text { platform }\end{array}$ & 8 & $2.9 \%$ & 1 & $0.4 \%$ & 8 & $2.9 \%$ & 40 & $11.2 \%$ \\
\hline $\begin{array}{l}\text { Variety of good } \\
\text { quality content }\end{array}$ & 20 & $7.3 \%$ & 11 & $4.2 \%$ & 22 & $8.0 \%$ & 76 & $21.3 \%$ \\
\hline $\begin{array}{l}\text { Suggestive content } \\
\text { increasing }\end{array}$ & 5 & $1.8 \%$ & 8 & $3.1 \%$ & 11 & $4.0 \%$ & 45 & $12.6 \%$ \\
\hline $\begin{array}{l}\text { Ease of } \\
\text { consultation with } \\
\text { brand }\end{array}$ & 9 & $3.3 \%$ & 26 & $10.0 \%$ & 19 & $6.9 \%$ & 2 & $0.6 \%$ \\
\hline $\begin{array}{l}\text { Achieving brand's } \\
\text { marketing goals }\end{array}$ & 8 & $2.9 \%$ & 33 & $12.6 \%$ & 12 & $4.4 \%$ & 11 & $3.1 \%$ \\
\hline $\begin{array}{l}\text { Creator's target } \\
\text { influence }\end{array}$ & 25 & $9.1 \%$ & 30 & $11.5 \%$ & 25 & $9.1 \%$ & 17 & $4.8 \%$ \\
\hline $\begin{array}{l}\text { Creator's marketing } \\
\text { impact }\end{array}$ & 21 & $7.7 \%$ & 27 & $10.3 \%$ & 15 & $5.5 \%$ & 24 & $6.7 \%$ \\
\hline Total & 274 & $100.0 \%$ & 261 & $100.0 \%$ & 275 & $100.0 \%$ & 356 & $100.0 \%$ \\
\hline
\end{tabular}

of the MCN as well as the creator's because of increased platform advertising commissions. [R4] is a reinforcing loop of revenue diversification. With MCN's support of diversifying channels, creators can verify their content channels (e.g., diverse online video platforms and even CATV programs) that lead to more advertising fees and more profit.

Next, there are reinforcing loops [R3], [R5], and [R6] generated by the increase of branded content production because of the MCN's support. The MCN business helps creators in a flexible and effective way to create branded content that is considered to be a major revenue model. [R3] MCN facilitates the creation of branded content for both creators and brands by taking over the tasks that are difficult for creators to handle alone (e.g., contracting, price setting, and communication for business collaboration). As a result, the revenue of both the creators and of MCN businesses is increased, thereby activating the MCN industry. [R5] explains the strengthening effect of a virtuous cycle that will lead to more production of branded content because of the increased popularity of creators as a result of an MCN business's support and investment. [R6] is another virtuous circle that leads to the popularity of the creator and the creation of other branded content by increasing the total number of views. 
Affiliate contract or copyright management is a difficult task for me to do by myself. I do not spend time managing it, so I can focus only on my content creation. I think business- to-business relationships enable big deals. I'm going to participate in the movie introduction of TV shows. If I handled this deal by myself, it would be very hard to do (Creator I).

[R10] Some MCN businesses continue to pursue activation by creating IP content. The "Dotty \& Sleepground" goods of the SandboxNetwork that are very popular among elementary school students are a good example. A comic book with their character became a best seller, and the CATV animation produced with their character has achieved an audience rating of $2.5 \%$, and other character products are loved by their fans (ChosunIlbo, 2016).

[R9] Outside investment is also an activator of the MCN industry. The popularity of creators increases according to the number of viewers and attracts investment from external capital. These phenomena that imply the growth potential of MCN businesses are now a big nurturer of the MCN industry. Although the MCN industry has yet to become well-established, various attempts and businesses were made possible because of the investment from external capital.

In some cases, the departure of a famous creator may hurt an MCN company. [B2] A famous creator's departure from a MCN company led to a 14\% drop in the company's stock (NewsTomato, 2016), suggesting that the influence of famous creators has increased and that the transfer of famous creators has had a big impact on the industry as a whole.

One video content platform suffered fluctuation resulting from a star creator's leaving. Some creators who have become uniquely independent establish their own private companies. PewDiePie's private company, PewDie Productions, had revenue of \$9.3 million in 2015. MCN companies lack a reason to keep big star creators from leaving them (MCN participant $B)$.

\section{Brand and Creator's Perspective}

As shown in Figure 3, the most important concern of a brand is "achieving brand's marketing goals." On the other hand, Figure 4 shows that the biggest concern of a creator is "total number of views." This difference in priorities causes problems.

[B1] Loop is an obstacle to the MCN industry because of such differences in perspective. Each stakeholder named a totally different factor. Brand participants called it "creator controls" and creators named this factor "coordinating with brands." In the case of a brand, achieving its marketing goal is the priority, so its attitude is to require a creator to deliver the desired marketing message to the target as efficiently as possible. [R8] As creator control becomes effective, ease of consultation with the brand increases; consequently, the brand partnership will increase and more branded content will be produced in the future.

Creator control is the biggest issue. These days many well-known creators claim their model fee at a celebrity level, and they even do not cooperate better than a celebrity. In some cases, the creator's channel is blocked because of the platform regulation ... Brand managers should endure the risk of being blocked. (Advertising agency $T$ )

[B1] On the other hand, creators often worry that such creator controls will lessen their autonomy. They are worried that existing subscribers may leave when they insert contrived marketing messages into their content that are not relevant to existing content. 


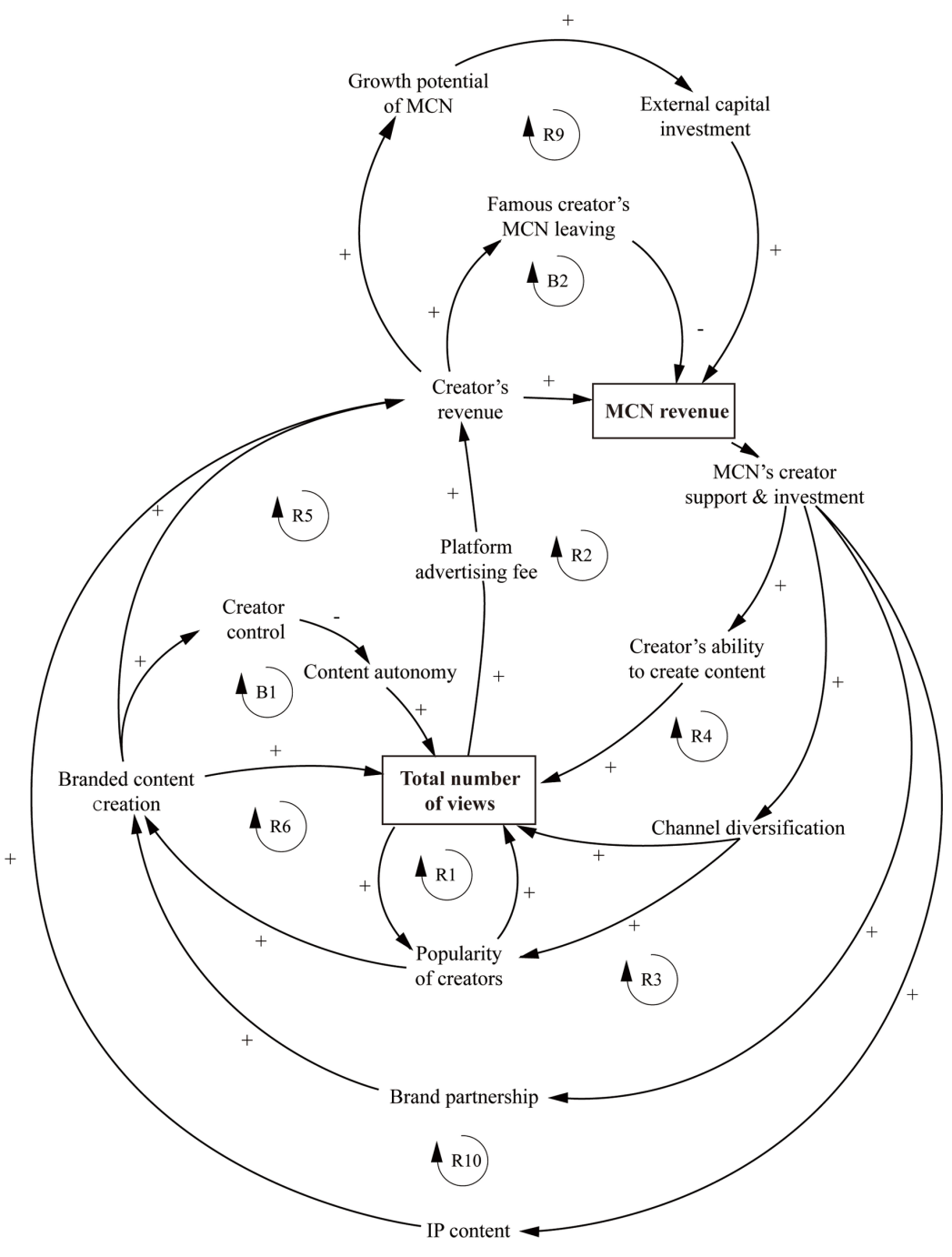

After producing branded content, I got a lot of swearing. There were also departing subscribers who said that the nature of the content had deteriorated. I did not want to make that branded content, but I could not stop in the midst of the terms of the contract, so I adjusted the message level again and again, but some viewers hated it. (Creator I)

Another issue from the brand's point of view is that it is difficult to evaluate the effectiveness of creators on marketing. Across the industry, evaluating the impact of a given creator is based on the number of her or his subscribers. [R7] It is hard to say that the number of subscribers reflects a creator's target influence or a creator's marketing influence. However, many of the brand managers and advertising agency staff interviewed were questioned about these influences.

MCN creator content is new and fresh, so there's a lot of approaches, but only a few get produced. Many advertisers cannot believe the effect. They say it's not yet verified. (Advertising agency R) 
Figure 3. CLD of brand's perspective

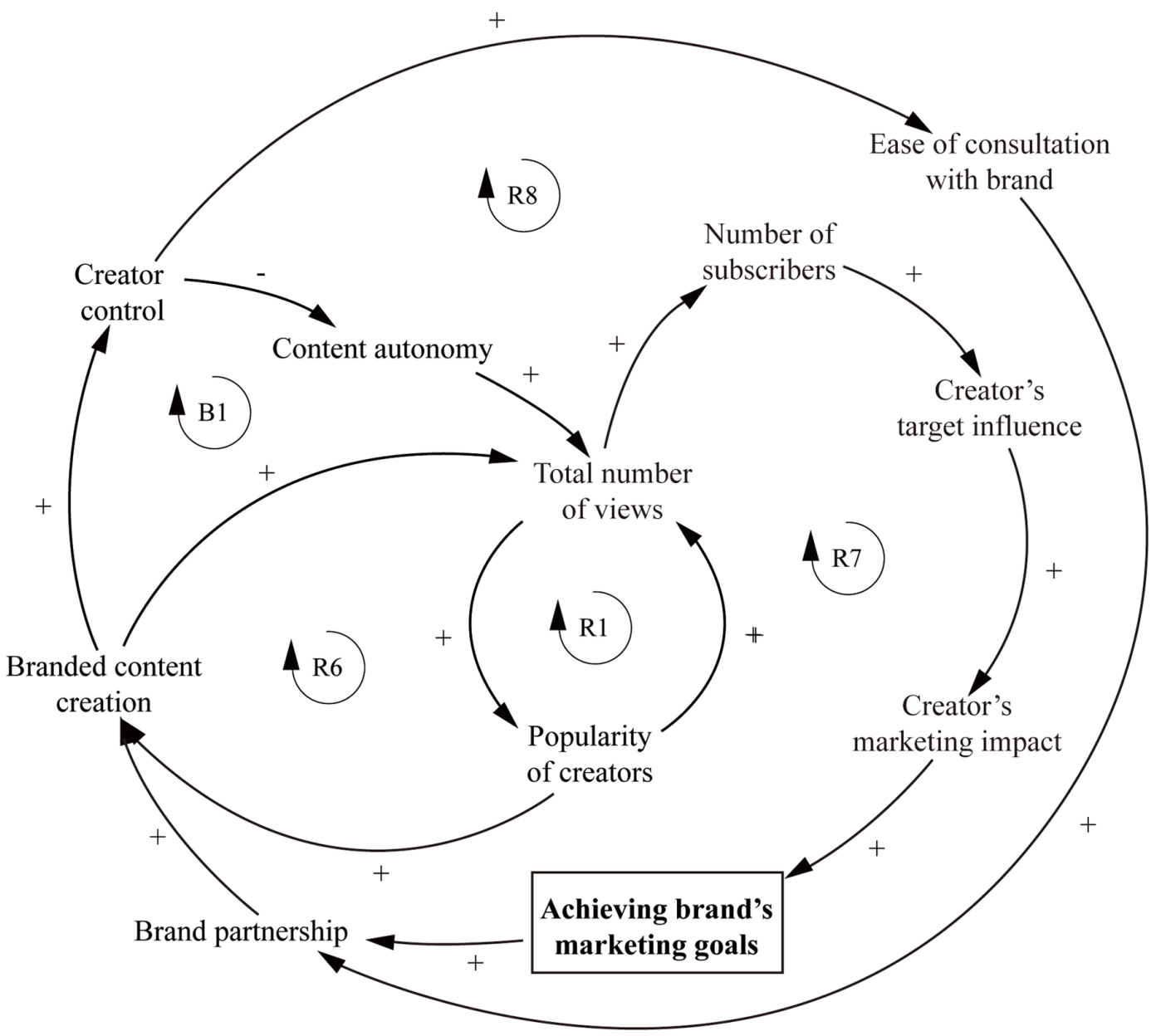

Creators have a lot of subscribers, many views... But we can't convince advertisers of how much of it is delivered as we intended and connected to actual attitude formation or action. Some MCN businesses provide performance reports, but I think it is not enough." (Advertising agency S)

Interviewees with successful branded content cases commented on positive experiences, and most of them had considerable understanding of creator content, so they left them unattended and made branded content without controls on creators.

Customers trust YouTube creators more than what the brand says directly. So, it's effective to make YouTube creators talk about the brand and product. (Brand manager P)

The creator was a very good fit with our marketing message and product attributes. We fixed very basic story lines and left the rest to the creators. The result was very satisfying. The number of visitors to the landing page was much higher than usual. (Brand participant $N$ ) 


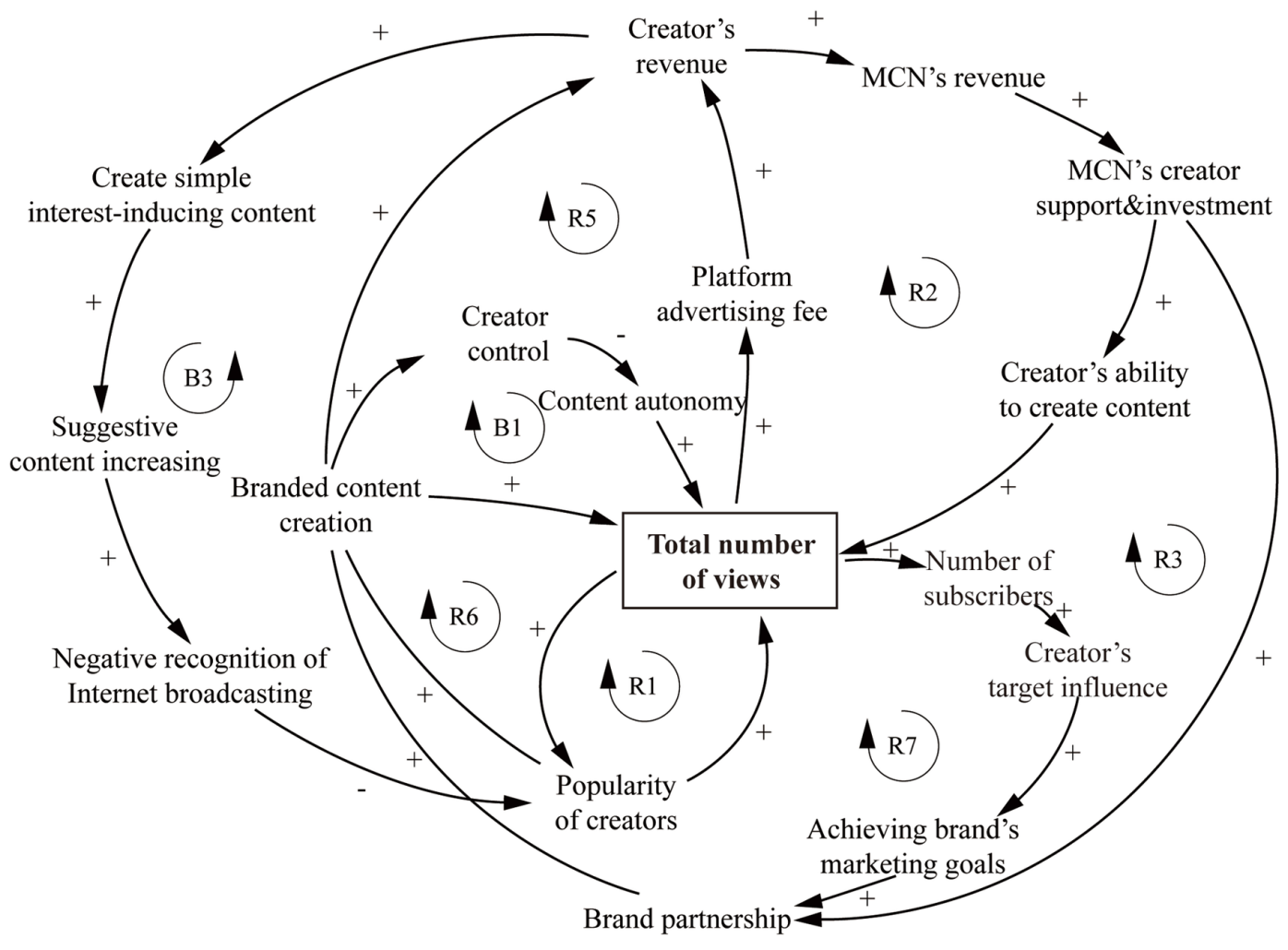

\section{Platform and User's Perspective}

The most interesting factor in terms of platform is the "users' entry into the platform." Raising the monthly active user (MAU) is the most important factor for platform operators because this statistic is directly linked to the platform's revenue.

As shown in Figure 5, the [R11], [R12] and [R13] loops show a win-win relationship between a platform and an MCN company. Loop [R11] increases the total number of views by enhancing the variety of good quality content, which was supported by the MCN business. [R12] From a user's point of view, if a variety of high-quality content is produced, it leads to more viewing and more user entry into the platform. [R13] This phenomenon also causes a content long-tail phenomenon by changing the viewing pattern of users. Content created by various creators on diverse subjects, rather than content by a few major broadcasters, will become popular.

Apart from these positive loops, the most talked-about part of user interviews concerned suggestive and sensational content. [B3] As the income of personal media creators grew and attracted attention, suggestive and sensational content became popular. That kind of content leads negative perception about creator content. It is obstacle to the MCN industry.

My kid is 7 years old, and she loves YouTube kids content and views it almost an hour a day. I think they should have some censorship on kid content. (MCN D)

Sometimes suggestive and sensational content becomes an issue. This issue leads prejudice about creators. I am upset when there is such prejudice. (Creator L) 


\section{Issue Analysis and Propositions}

The final CLD and the issues derived from it are shown in Figure 6. We found four issues: (1) creators and brand managers' perception gap about the role of creators, (2) coordination between creators and the brand because of perception mismatches, (3) doubt about creators' marketing and target influence, and (4) suggestive and sensational content. Based on these issues, we propose the corresponding propositions (see Table 3).

First, there is a discrepancy in how creators are recognized (1). Recognition mismatches between creators and marketers can lead to problems in branded content production, which is MCN's largest revenue model. Brand managers try to control the creators to effectively deliver the marketing message, and the creator tries to accommodate the needs of marketers while maintaining the character of their channel. In order to solve such problems, it is necessary to constantly make an issue of the concept and character of the creator and educate the brand marketers and advertisers.

Figure 5. CLD of platform and user's perspective

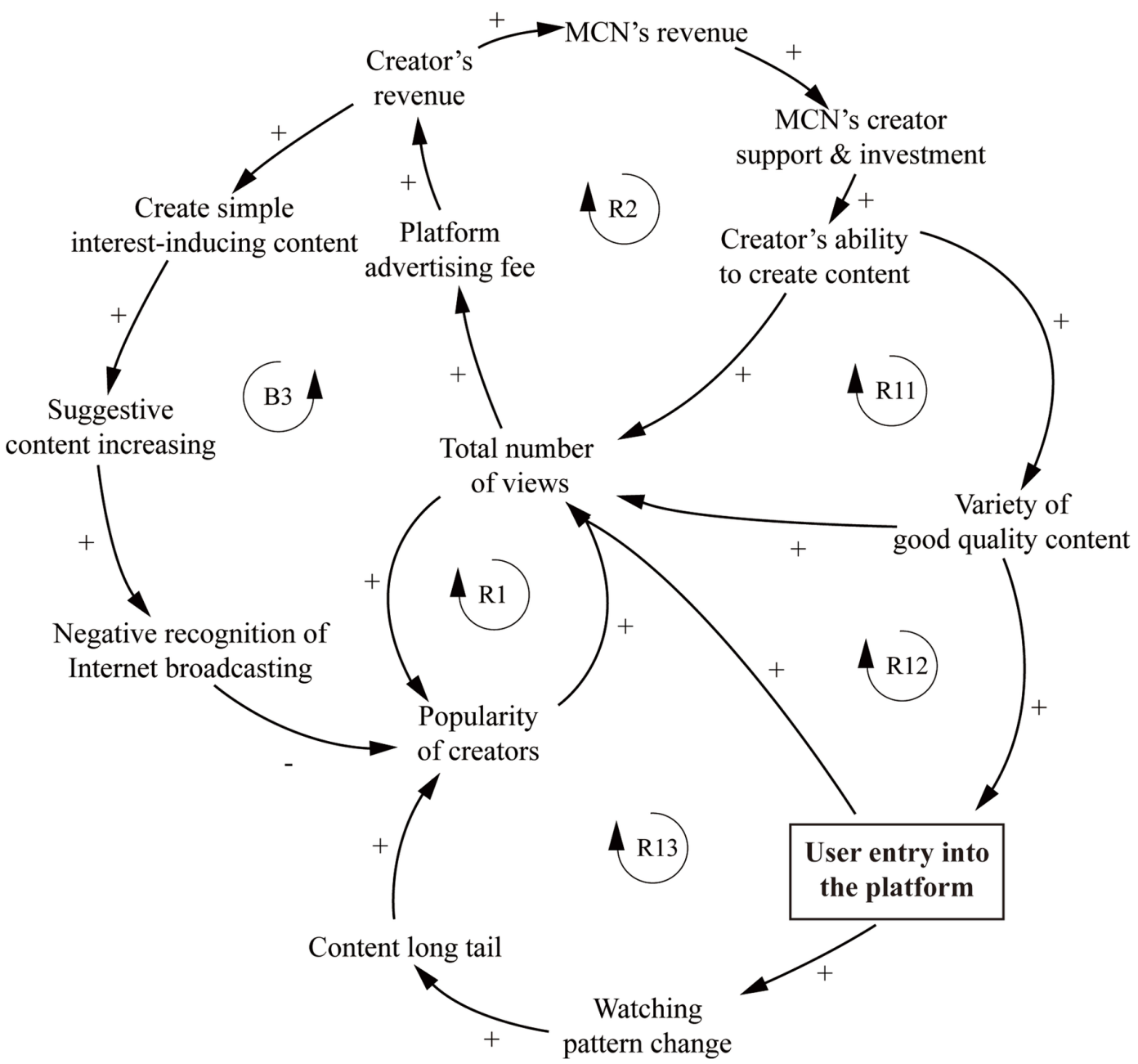




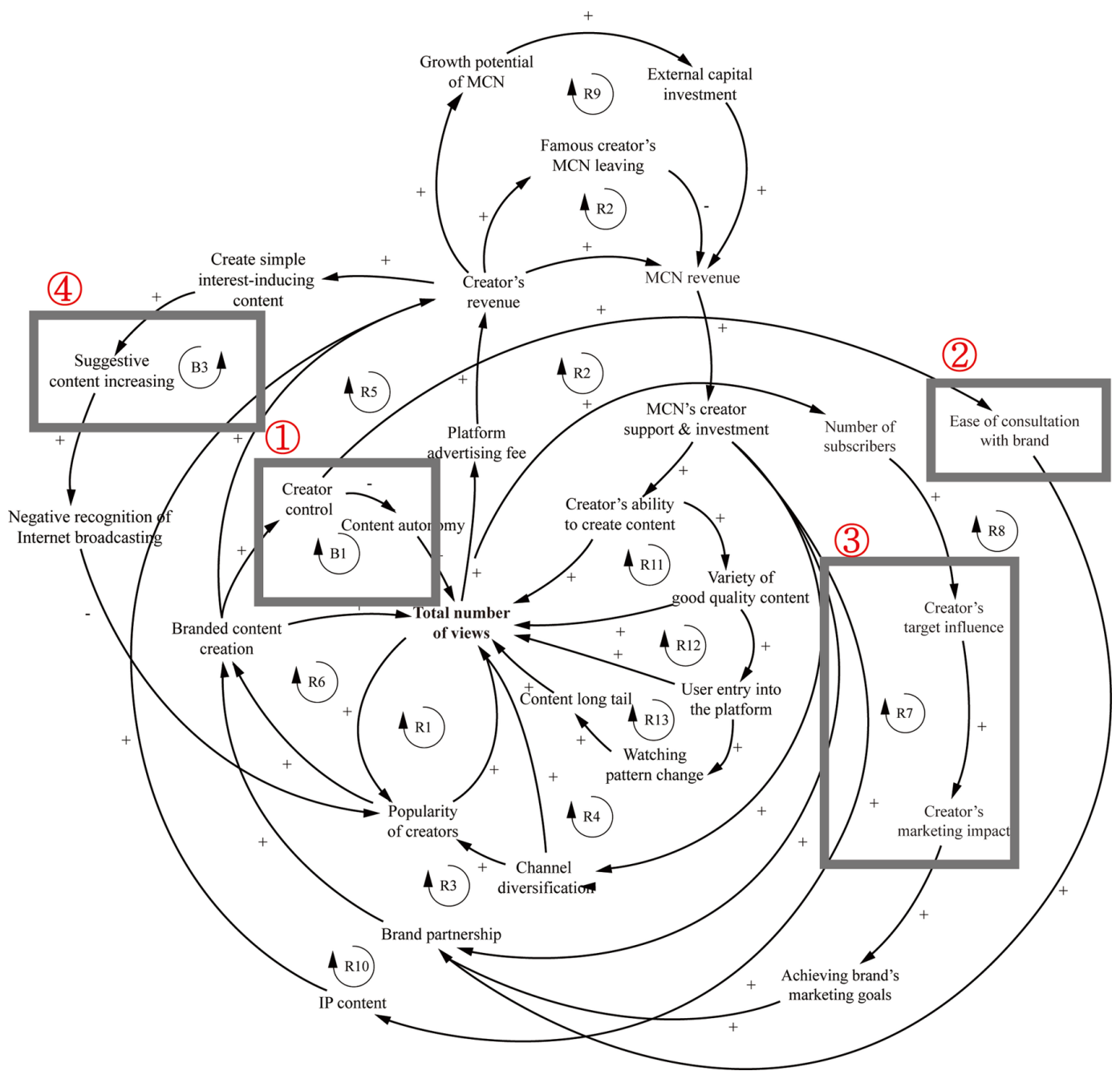

Creators have three characteristics. First, creators are influencers and have the same characteristics as celebrities. Second, at the same time, they are producers of content. And lastly, they are media channel by themselves. Marketers need to understand all three characteristics and collaborate with them. Marketers still misunderstand creators' roles. (MCN participant C)

If you leave creation to the creator completely, the result will be better. We value the creators the most. We don't make branded content which will harm the creator's identity. (MCN participant A)

Second, there is the problem of coordinating between the creator and the brand (2). Although the MCN company is coordinating the two as an intermediary, there seems to be room for further improvement. The solution to this problem is to increase the professional competence of the AEs of the MCN companies who also act as an advertising agency's AE. The advertising agency's AEs perform an intermediary role between the advertiser and the producer. Because an MCN company is focused on producing branded content, it is essential to increase the professionalism of the AEs. 
Table 3. MCN industry activation propositions

\begin{tabular}{|l|l|l|}
\hline No & \multicolumn{1}{|c|}{ Problem } & \multicolumn{1}{|c|}{ Proposition } \\
\hline (1) & $\begin{array}{l}\text { Recognition mismatches of creator's role } \\
\text { between creators and marketers }\end{array}$ & $\begin{array}{l}\text { MCNs should educate brand marketers about the true } \\
\text { function of creators }\end{array}$ \\
\hline (2) & $\begin{array}{l}\text { Coordinating between creators and the } \\
\text { brand }\end{array}$ & $\begin{array}{l}\text { MCNs should strengthen the AE's expertise (Recruit } \\
\text { experienced workers or train existing staff) }\end{array}$ \\
\hline (3) & $\begin{array}{l}\text { Brand managers' doubts about creators' } \\
\text { marketing and target influence }\end{array}$ & $\begin{array}{l}\text { MCNs should develop an index to measure the } \\
\text { creators' marketing performance and target impact }\end{array}$ \\
\hline (4) & Suggestive and sensational content & $\begin{array}{l}\text { Regulations should be introduced to encourage } \\
\text { stimulating and sensible content }\end{array}$ \\
\hline
\end{tabular}

Some MCN often just like selling a media program. Popular creators are suggested in every proposal. The one creator cannot fit all brands. When the MCN makes an offer, they should describe the characteristics and strengths of the creator and explain the reasons why this creator is going to be suitable for this brand. But I feel like a salesperson who is just selling rather than planning." (Advertising agency $R$ )

Third, there is a question about creators' marketing and target influence (3). As mentioned earlier, many marketers were skeptical of the relationship between the total number of creators' views and the marketing influence of these views.

There is a question about the marketing effectiveness of creator content. The marketing effectiveness of those specific viewers has not yet been proven. (Brand $O$ )

A famous creator's collaboration fee is very expensive. The model fee is almost that of famous comedian's. Even if creators are less popular with the masses, they tend to have a higher specific target preference, so brands with higher target fits tend to produce branded content. With them the campaign I did was able to track the conversion rate, and the rate was really nice. (Advertising agency T)

These problems can be solved through the development of impact indicators. Each time a new media emerges, researchers have developed an evaluation index by comparing the effect with that of existing media. If a credible evaluation index is developed, it will be possible to increase trust in the content of MCN companies.

Finally, there is a problem with suggestive and sensational content (4). Unlike the traditional broadcasting, irritating and sensational content is broadcasted without censorship. This problem should be solved by the related regulations of the platform, government agencies, creators, and users' self-restraint.

\section{DISCUSSION AND IMPLICATIONS}

\section{Discussion}

We have developed a proposition for each of the problems derived from the CLD and conducted a FGD to evaluate the importance of these propositions. The FGD was conducted one year after the interviews. A validation FGD was conducted with one MCN participant and two advertising agency employees who have conducted expert interviews. All members agree with the issues and propositions that have been derived from this study of their perspectives. 
The MCN industry activation propositions are summarized in Table 4. To solve the first issue (1), MCNs should educate brand marketers about the true roles of creators. If marketers are aware of the creators' complex roles (celebrity, producer, and media at the same time) collaboration between them could be easier. Based on an understanding of the characteristics of the creators' content, it becomes possible to produce seamless branded content. To create successful branded content, marketers should ensure that the creators' autonomy.

The second issue - coordination between creator and brand (2) - could be solved by increasing MCN AEs' expertise. Affiliations with brands and creators is one major role of MCN. But the recognition mismatch causes a problem when making branded content. Educating MCN AEs how to collaborate with brand marketers would be helpful. Recruiting experts from advertising companies or brand marketers could be another option. "They have to offer a branded content plan based on an understanding of the personality and characteristics of the creators and coordinate the production process, but they did not" (Advertising agency S). MCN companies should ensure their AEs have the expertise to supervise production of branded content efficiently and strategically.

Doubt about a creator's marketing and target influence, the third issue, could be solved by developing an evaluation index to measure the creator's impact. Fans want to support and follow their favorite creators. They view their favorite creators as extensions of themselves (Belk \& Coon, 1993). Because of this influence, creators are considered for the creation of branded content but viewed warily in the absence of performance measures. As a remedy, this study proposes that MCN and government agencies develop an evaluation index. Such an index would bolster marketer's confidence in their decisions to make branded content. "After a year, the problems remain in the same status. There are not enough criteria to objectively evaluate the marketing effect" (Brand marketer P).

Finally, either government or platforms themselves could resolve the fourth issue of suggestive and sensational content (Kim, 2016). In interviews, parents, especially, were concerned about the suggestive and sensational nature of creators' content. Lee and $\mathrm{Yu}$ (2017) found in their analysis of MCN content that each MCN clip contained on average 38.3 instances of harmful content. This is a huge number compared with traditional broadcasting. Online content is especially vulnerable to containing harmful content because of a lack of regulation or age limits for viewers. Regulators should pursue the voluntary collaboration of users, $\mathrm{MCN}$, and creators in seeking to control creation of stimulating and sensible content.

\section{Limitations and Future Research Directions}

This study has several limitations. First, the Korean domestic MCN industry is still in a formative stage and there are limitations on the collection and verification of activation factors. As for a quantitative analysis of this domestic Korean MCN industry, when its fate is settled more empirical verification will be required, starting with the development of quantitative analytical tools for its content. Second, because this is an interview-based exploratory study, it may reflect the interviewers' biases, despite their intention and best efforts to remain objective. Third, after the development of

Table 4. MCN industry activation propositions

\begin{tabular}{|c|c|c|c|}
\hline No & Proposition & Subject & Collaboration \\
\hline (1) & $\begin{array}{l}\text { Educate the brand marketers about creators' } \\
\text { concepts and character }\end{array}$ & $\mathrm{MCN}$ & $\begin{array}{l}\text { Brand marketer, } \\
\text { Advertising agency }\end{array}$ \\
\hline (2) & $\begin{array}{l}\text { Increase MCN AEs' expertise (recruit experts } \\
\text { or educate them) }\end{array}$ & $\mathrm{MCN}$ & \\
\hline (3) & $\begin{array}{l}\text { Develop an evaluation index of } \\
\text { creators' marketing and target influence index }\end{array}$ & $\begin{array}{l}\text { MCN, Government } \\
\text { agencies }\end{array}$ & $\begin{array}{l}\text { Government agencies, } \\
\text { Research institute }\end{array}$ \\
\hline (4) & Regulate suggestive and sensational content & $\begin{array}{l}\text { Government } \\
\text { agencies, Platform }\end{array}$ & Users, MCN, Creators \\
\hline
\end{tabular}


the CLD, the process of complementing it through an expert group FGD may have been incomplete through inadvertent failure to reflect the opinions of specific groups of experts. Future research should pursue the development of empirical indicators for comparisons with existing media through quantitative analysis of MCN business's content. If an empirical indicator of the marketing influence of creators can be developed, it will be presented to the marketers of brands as the main criteria for decision making.

\section{Implications for Research and Practice}

This study has several implications for research. First, we analyzed the causal relationships and influences of various factors to gain an understanding of the structure of the MCN industry. Most of the previous studies of the current status of this industry relied on a literature review (Gardner, 2015; Kang, 2015; Cunningham \& Silver, 2016; Gardner \& Lehnert, 2016; Kim, 2016; Yim, 2016; Song, 2016). In contrast, we conducted in-depth interviews with 26 qualified professionals and 14 users to figure out the causal relationships within the industry, which is not yet well-known. The CLDs summarized in this study will provide a basis for understanding the structure of the MCN industry for future research.

Second, we derived issues from the viewpoint of various stakeholders as a way to gain a comprehensive understanding of the MCN industry. Despite the diversity of the industry stakeholder relationships (e.g., MCN participants, creators, brand managers, advertising agency AEs, platform participants, and users), most previous studies focused on the creators, MCN participants, and users (Gardner \& Lehnert, 2016; Lee \& Song, 2016).

Third, the propositions proposed in this study were validated by conducting an expert FGD twice at different timetables to validate the propositions' criticality and to exclude researchers' subjectivity and temporal issues. Although qualitative research based on in-depth interviews is a research technique prone to involve the subjectivity of the researchers, we have proposed a methodology to verify the propositions by conducting two-stage interviews with experts at different times. The four propositions are not subjective interpretations of the researchers or temporary opinions. Even after a year, the issues are proven to remain urgent and important for the industry. The adequacy of propositions has been verified. Performing additional two-stage interviews with experts over time can supplement their validity.

Fourth, this study contributes to widening the diversity of the research by studying the emerging industry through a research methodology of system thinking. Through this approach we were able to grasp both positive and negative causal relationships between each factor and derive issues from both sets of relationships. This methodology also proved to be a meaningful way to suggest propositions for each of these problems and to suggest ways to activate the MCN industry based on a thorough understanding of the industry structure.

This study has several implications for practice as well. First, the major issues and related propositions will help each stakeholder to gain insights about the industry. The issues and propositions discussed in this study are based on the vivid testimonials from members of the various categories of stakeholders that constitute the MCN industry ecosystem. By drawing out the opinions of major stakeholders on the industry's comprehensive issues and arriving at alternatives, this study presents a big picture of how the MCN industry operates and how it can be activated.

Second, for MCN participants the most urgent issue is the improvement of the expertise of AEs. Education of brand marketers on the role of creators is also necessary to smooth the route to easier and more efficient production of branded content. Also, MCN companies should be attentive to developing and implementing ways to evaluate the marketing influence and target influence of creators.

Third, creators need to think about how to effectively convey brand messages while retaining their own content personality and freshness. This accumulated know-how will bring great benefits to future branded content production. Creator need to avoid producing stimulating and sensational 
content. In the long run, creators who create good content will attracts broader audiences and promotes collaboration with a brand.

Fourth, brand marketers and advertising company representatives should re-recognize the role of creators and become comfortable with it. Understanding the role and nature of creators makes it possible to create effective branded content. Creators should be given only basic guidelines and left to work autonomously.

Lastly, platform managers are advised to make appropriate regulations and censorship. Many interviewees worried about sensational and stimulus content because kids can watch it without any limitation. Some forms of censorship and regulation are need. 


\section{REFERENCES}

Akkermans, H., \& van Helden, K. (2002). Vicious and virtuous cycles in ERP implementation: A case study of interrelations between critical success factors. European Journal of Information Systems, 11(1), 35-46. doi:10.1057/palgrave.ejis.3000418

Analysys. (2016). Chinese Red Industry Special Research Report 2016. Retrieved from https://www.analysys. cn/analysis/detail/1000232/

AsiaToday. (2016). Animax opened 'Dotty\&Sleepground TV'and recorded top rating of animation channel. Retrived from http://www.asiatoday.co.kr/view.php?key=20160805001407221

BBC. (2016). Wang Hong: China's online stars making real cash. Retrived from https://www.bbc.com/news/ world-asia-china-36802769

Belk, R. W., \& Coon, G. S. (1993). Gift giving as agapic love: An alternative to the exchange paradigm based on dating experiences. The Journal of Consumer Research, 20(3), 393-417. doi:10.1086/209357

ChosunIlbo. (2016). For teenagers, the MCN is the "mainstream" ... Beyond YouTube Watches Major Broadcasting Market. Retrieved from http://news.chosun.com/site/data/html_dir/2016/10/22/2016102200648.html

Cunningham, S., Craig, D., \& Silver, J. (2016). YouTube, multichannel networks and the accelerated evolution of the new screen ecology. Convergence, 22(4), 376-391. doi:10.1177/1354856516641620

DefyMedia. (2015). Millenials Ages 13-24 Declare It's Not Just The Cord, TV Content Doesn't Cut It - Digital Delivers More Relatable and Entertaining Programming. Retrieved from http://www.defymedia.com/2015/03/03/ millennials-ages-13-24-declare-just-cord-tv-content-doesnt-cut/

Flick, U. (1998). Qualitative research: Relevance, history, features. An Introducation to Qualtitative Research.

Gardner, J. (2015). Applications of the Multi-Channel Network Model to New Media Formats.

Gardner, J., \& Lehnert, K. (2016). What's new about new media? How multi-channel networks work with content creators. Business Horizons, 59(3), 293-302. doi:10.1016/j.bushor.2016.01.009

Jang, Y.-J., Cho, E.-Y. \& Kim, H.-W. (2015). An Exploratory Study on Online Prosocial Behavior. Knowledge Management Research, 16(1), 225-242.

Kang, B. H. (2015). Current State of Multi-Channel Network and Prediction toward Media Industry. Korea Entertainment Industry Association.

Kim, Chi Ho., (2016). Present and Future of MCN Business. Human content, (40), 167-187.

Kim, H. W., Chan, H. C., \& Gupta, S. (2015). Social media for business and society. Asia Pacific Journal of Information Systems, 25(2), 211-233. doi:10.14329/apjis.2015.25.2.329

Koh, Moonjung., and Youn, Sugmin. (2016). Investigation on the Business Model of Multi-Channel Network of Online Platform. Korean Telecommunications Policy Review, 23(1), 59-94.

KOTRA. (2016) Min Ju Kang, China's Wanghong(网红) 4.0 era, from phenomena to industry. Retrived form http://news.kotra.or.kr/user/globalAllBbs/kotranews/album/2/globalBbsDataAllView.do?dataIdx=155139\&c olumn $=\&$ search $=\&$ searchAreaCd $=\&$ searchNation $C d=\&$ searchTradeCd $=\&$ searchStartDate $=\&$ searchEndDa te $=\&$ searchCa

Kyunghyang News. (2018). The era of personal media creators. Retrieved from http://news.khan.co.kr/kh_news/ khan_art_view.html?artid=201803040944031\&code=940100

Lee, H., Choi, H.-S., and Kim, H.-W. (2012). A Study on the Platform Business of a Game Console Industry by Causal Loop Diagram (CLD). Journal of Korea Information Science Society, 10(3), 169-177.

Lee, Harim. and Yu, Hongsik. (2017). An Exploratory Study on Negative Characteristics of Multi-Channel Network Content, and Introduction of Relevant Regulations. Journal of Speech. Media \& Communication Association, 16(1), 119-152. 
Lee, J. U., Seo, K. J., \& Kim, H. W. (2014). An exploratory study on the cloud computing services: Issues and suggestion for the success. Asia Pacific Journal of Information Systems, 24(4), 473-491. doi:10.14329/ apjis.2014.24.4.473

Lee, Y.J., and Song, J. (2016). An Exploratory Study on Acceptance of Personal Webcasting Contents: Focusing on Use Characteristics and Attitudes toward Advertising. Korea Association for Broadcasting \& Telecommunication Studies, 96, 68-103.

Lu, Y., Chen, A., \& Gupta, S. (2017). Enhancing the decision quality through learning from the social commerce components. Journal of Global Information Management, 25(1), 66-n/a.

Neuman, W. L. (2013). Social research methods: Qualitative and quantitative approaches. Pearson education.

NewsTomato. (2016). Africa TV, regulatory and BJ leaving slump Stock drop 13\% in a week. Retrieved from http://www.newstomato.com/readNews.aspx?no=700404

Platum. (2017). Startup investment trend in South Korea: Fintech and AI are investor favorites. Retrieved from http://platum.kr/archives/84954

Shaw, C., \& Wainwright, D. (2007). Developing a CSF Causal Loop Model for Managing IT Projects: A Case Study of an Inter-Organisational Healthcare Pathology IT System. ICIS 2007 Proceedings, 24.

Shin, I.G., Shon, Y.G., Lee, J.W., \& Jung, Y.J. (2014). Effects of temporal distance, product type and advertising message to consumer's information process: On a social commerce. Advertising Research, 102, 150-180.

Song, M. (2016). A study on business model of global top five MCN media companies: Based on the theory of disruptive innovation. Journal of Broadcasting and Telecommunications Research, 96, 38-67.

Sterman, J. D. (2001). System dynamics modeling: Tools for learning in a complex world. California Management Review, 43(4), 8-25. doi:10.2307/41166098

Sutanto, J., Kankanhalli, A., Tay, J., Raman, K. S., \& Tan, B. C. (2008). Change management in interorganizational systems for the public. Journal of Management Information Systems, 25(3), 133-176. doi:10.2753/MIS07421222250304

Tubefilter. (2014). The Average YouTube CPM Is \$7.60, But Making Money Isn't Easy. Retrieved from http:// www.tubefilter.com/2014/02/03/youtube-average-cpm-advertising-rate/

Variety. (2014, 08 05). Survey: YouTube Stars More Popular Than Mainstream Celebs Among U.S. Teens. Retrieved from http://variety.com/2014/digital/news/survey-youtube-stars-more-popular-than-mainstreamcelebs-among-u-s-teens-1201275245/

Weinstein, B. (2015). Interview with Brent Weinstein, Head of Digital Media. United Tal.

Yim, J. (2016). Models of Responding Strategy of Legacy Media to MCN in the U.S. Journal of Broadcasting and Telecommunications Research, 95, 35-63.

YouTube. (n.d.). Multi-Channel Network (MCN) overview for YouTube Creators. Retrieved from https://support. google.com/youtube/answer/2737059?hl=en

Yu, S.-I., Lee, S.-H., and Kim, H.-W. (2013). An Exploratory Study on Smart Work: A Systems Thinking Approach. Entrue Journal of Information Technology, 12(3), 57-73. 
Yoon-Jin Choi is currently a Doctoral student in the Graduate School of Information at Yonsei Universi. She is CEO of data analysis company Mondata, Inc. She has a BA and MA from Yonsei University and worked as a marketing communication planner at TBWA KOREA. Her major interests are digital business, big data analysis, and digital media.

Hee-Woong Kim is a professor in the Graduate School of Information at Yonsei University. He was a faculty member in the Department of Information Systems and Analytics at the National University of Singapore. His research interests include digital business and IS management. His research work has been published in MIS Quarterly, Information Systems Research, Journal of the Association for Information Systems, and Journal of Management Information Systems (JMIS). He has served on the editorial boards of the JAIS and IEEE Transactions on Engineering Management. 